\title{
Distribuição e Impacto da Sigatoka-Negra na Bananicultura do Estado do Acre
}

\author{
Maria de Jesus B. Cavalcante ${ }^{1}$, Claudenor P. de Sá1, Francisco C. da Rocha Gomes ${ }^{1}$, Tarcísio M. de Souza \\ Gondim², Zilton J. M. Cordeiro $^{3}$ \& Jorge L. Hessel ${ }^{4}$
}

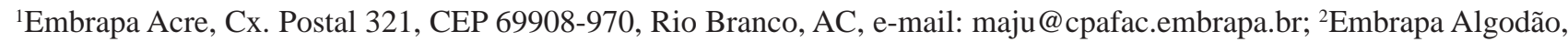
Cx. Postal 174, CEP 58107-720, Campina Grande, PB; ${ }^{3}$ Embrapa Mandioca e Fruticultura, Cx. Postal 007, CEP 44380-000, Cruz das Almas, BA; ${ }^{4}$ SSV- DFA, Acre, Cx. Postal 150, CEP 69901-180, Rio Branco, AC

(Aceito para publicação em 29/03/2004)

Autor para correspondência: Maria de Jesus Barbosa Cavalcante

CAVALCANTE, M.J.B., SÁ, C.P., GOMES, F.C.R., GONDIM, T.M.S., CORDEIRO, Z.J.M. \& HESSEL, J.L. Distribuição e impacto da sigatoka-negra na bananicultura do estado do Acre. Fitopatologia Brasileira 29:544-547. 2004.

\section{RESUMO}

A sigatoka-negra (Mycosphaerella fijiensis) é a doença de maior severidade que afeta as cultivares de banana (Musa spp.) de importância econômica no mundo. Foi constatada no Brasil em 1998, no Estado do Amazonas, e tem se disseminado pelo Estado do Acre, atacando severamente as cultivares do Subgrupo Terra (AAB). Realizou-se um diagnóstico da sigatoka-negra e dos impactos econômicos causados por esta doença nos municípios do Estado do Acre. Foram visitados plantios em 16 municípios e amostras de folhas de bananeiras com sintomas característicos da doença foram coletadas para diagnóstico. Verificou-se que a sigatoka-negra estava presente em todos os municípios visitados. As conseqüências econômicas da doença podem ser evidenciadas pela redução de $42 \%$ na produção total de banana do Estado do Acre no período de 2000/2001, enquanto o valor da produção foi reduzido em $47 \%$ no ano de 2001, com repercussão nos diversos segmentos da cadeia produtiva. Nesse aspecto, observou-se que os municípios de Plácido de Castro e Acrelândia, foram os mais afetados pela sigatoka-negra.

Palavras-chave adicionais: Mycosphaerella fijiensis, Amazônia, banana, produção.

\section{ABSTRACT}

Distribution and impact of black sigatoka in the banana plantations in the State of Acre

Black sigatoka (Mycosphaerella fijiensis) is the most severe disease affecting banana (Musa spp.) cultivars in terms of economic importance in the world. It was verified in Brazil in 1998, in the state of Amazonas, and has since spread throughout the state of Acre, severely attacking the cultivars of the Subgroup Plantain (AAB). This study was performed to diagnosis the occurrence of black sigatoka and the economic impact caused by the disease in the municipal districts of
Acre. Visits to 16 municipal districts were made and samples of banana leaves with characteristic symptoms of the disease were collected for diagnosis. Black sigatoka was verified to be present in all municipal districts visited. The economical consequences of the disease are shown in a $42 \%$ reduction in total banana production in the State of Acre between 2000 and 2001, while the banana production fell another $47 \%$ in 2001, creating repercussions for diverse segments of the productive chain. Plácido de Castro and Acrelândia municipal districts were observed to have suffered the worst effects of black sigatoka.
A cultura da bananeira (Musa spp.) apresenta uma participação significativa na economia rural do Acre. As culturas da bananeira, laranjeira (Citrus sinensis L.) e cafeeiro (Coffea arabica L.) representam $85 \%$ do valor bruto de produção (VBP) das lavouras permanentes do Estado. Destas lavouras, a bananeira apresentou a maior participação, com aproximadamente $49 \%$ do VBP das culturas perenes (IBGE, 2002).

Em 1999, a bananicultura no Acre ocupou uma área de plantio de 6.680 ha com rendimento médio de 1.151 cachos por hectare. A maior parte da produção concentrou-se na região do baixo rio Acre, com 47\% da área colhida e 43\% da produção de todo Estado (IBGE, 2002). Nesta área destacam-se como maiores produtores os municípios de Acrelândia e Plácido de Castro.

A sigatoka-negra, causada pelo fungo Mycosphaerella fijiensis Morelet [fase anamórfica: Pseudocercospora fijiensis (Morelet ) Deighton], é a doença mais importante da bananicultura mundial (Marin et al., 2003). Os sintomas são caracterizados pela presença de estrias marrom na face inferior da folha, progredindo para estrias negras que formam lesões necróticas destruindo toda a área foliar resultando em redução da produção (Marin et al., 2003). Apresentando ampla distribuição geográfica, a sigatoka-negra causa a morte precoce das folhas infetadas sendo responsável por perdas superiores a 50\% da produção (Stover \& Simmonds, 1987).

Descrita pela primeira vez nas ilhas Fiji, em 1963, com o nome de raia negra ("Black Leaf Streak”), esta doença foi constatada em Honduras em 1972 ocasionando uma epidemia. Em 1979 chegou a Costa Rica (Cordeiro \& Matos, 2001). Atualmente o agente causal da doença está disseminado por toda América Central, e em algumas regiões da África e Ásia. 
Distribuição e impacto da sigatoka-negra na bananicultura...

Na América do Sul, a sigatoka-negra já foi constatada na Colômbia, Venezuela, Equador, Peru e Bolívia (Cordeiro \& Matos, 2001). No Brasil, foi constatada em fevereiro de 1998 nos municípios de Tabatinga e Benjamin Constant, Estado do Amazonas (Pereira et al., 1998). Atualmente está presente em todos os estados da região Norte e no Mato Grosso (Gasparotto et al., 2001).

No Estado do Acre, a sigatoka-negra foi constatada no município de Rio Branco, em novembro de 1998, na coleção de cultivares de bananeiras do Campo Experimental da Embrapa Acre (Ritzinger et al., 1999).

Para o Estado do Acre, cujo cultivo da bananeira ocupa a maior área dentre as espécies frutíferas plantadas, a sigatokanegra constitui sério problema uma vez que seus plantios são constituídos das cultivares Maçã, Prata e D’angola (Comprida subgrupo Terra), todas altamente suscetíveis à doença (Cavalcante et al.,1999 b, c). Outro aspecto importante a ser destacado está relacionado ao baixo nível tecnológico empregado no cultivo e transporte da produção. Este fato favorece a dispersão da doença e compromete a produtividade, além da qualidade do produto exigido nos mercados consumidores abastecidos pela produção acreana.

Considerando-se a rápida dispersão e visando retardar ao máximo a sua introdução nas regiões onde a bananicultura tem maior expressão econômica, realizou-se um diagnóstico da doença nos municípios produtores do Acre para tomada das providências quanto às ações a serem implementadas com vistas à convivência e controle da sigatoka-negra. Além da obtenção dos impactos econômicos causados pela doença na bananicultura acreana.

O levantamento da doença foi realizado por meio de expedições de coleta, no período de dezembro de 1998 a dezembro de 2000, em plantios de bananeira nos municípios de Acrelândia, Assis Brasil, Brasiléia, Bujari, Capixaba, Cruzeiro do Sul, Epitaciolândia, Mâncio Lima, Plácido de Castro, Porto Acre, Rio Branco, Rodrigues Alves, Senador Guiomard, Sena Madureira, Taraucá e Xapuri.

Coletaram-se amostras de folhas com sintomas típico da doença, utilizando-se 30 plantas de cada município das cultivares Prata, Maçã e D’Angola. As amostras foram examinadas no laboratório de Fitopatologia da Embrapa Acre, utilizando-se raspagens e cortes histológicos manuais, montados em lactofenol de Amann com e sem adição de azul de algodão (Tuite, 1969, Fernandez, 1993, Hawksworth et al., 1995). As preparações foram examinadas num microscópio Leica DMLS, acoplado com câmara fotográfica Leica MPS 30 e as estruturas importantes foram fotografadas (conídios e conidióforos).

Nas amostras que apresentaram dúvidas no diagnóstico foram realizadas análises por meio de pequenos cortes da área lesionada da folha e colocada para aquecimento em lactofenol de acordo com metodologia de Stover (1972) para posterior visualização dos conídios e conidióforos característicos do patógeno.

Os dados referentes à evolução da área plantada, área colhida, volume da produção, rendimento médio, valor da produção, e preço médio foram obtidos da Pesquisa Agrícola Municipal (PAM) para o período de 1996 e 2001 (IBGE, 2002). Os valores da produção do período foram corrigidos pelo IGPDI para o ano de 2001.

Por meio de observações microscópicas das amostras, foi diagnosticada a presença da doença nos bananais em todos os municípios, ou seja, a incidência da doença foi de 100\% nas áreas visitadas confirmando resultados anteriores (Cavalcante et al., 1999 a). Este resultado indica uma fácil e rápida disseminação do patógeno nos bananais do Acre, principalmente pelas condições climáticas propícias, temperatura e umidade médias de $24,5^{\circ} \mathrm{C}$ e $84,4 \%$, respectivamente (Acre, 2000), que favorecem o desenvolvimento da doença.

A maioria dos produtores de banana do Acre utiliza a cultivar D’Angola, que é preferencialmente consumida pela população local, independente da classe social, na forma de mingau, in natura, frita, cozida e doces (Gondim et al., 2001).

O crescimento do consumo local e o escoamento da produção para os mercados do Amazonas, Rondônia, Mato Grosso e Goiás vinham incrementando o plantio de novas áreas e em dois anos (1997-1999), o volume de produção em cachos cresceu 61\%. Porém, o período de 2000 a 2001 foi marcado por declínio de $42 \%$ na produção do estado, provavelmente devido à ação da sigatoka-negra (Figura 1).

As conseqüências da manifestação da doença podem ser evidenciadas a partir da análise do comportamento das variáveis: volume da produção, área colhida e rendimento por hectare, período 1997/2001 (Figura 1). Observa-se que a partir de 1999, período do estabelecimento da doença no Acre, todas as variáveis apresentaram valores decrescentes. O declínio da curva da área colhida é justificado pela diminuição da produção ocasionada pelo decréscimo do rendimento médio e pela decisão dos produtores em diminuir os plantios (Figura 1).

Referindo-se aos preços, observou-se que os mesmos mantiveram-se estáveis durante o período, não sendo influenciados pela variação do volume da produção. Esse fato pode ser explicado pela proibição das exportações, que contribuiu para o aumento da oferta da banana no mercado interno que, por sua vez, compensou a queda da produção.

Considerando os aspectos analisados, observa-se que em 2001, após o estabelecimento da doença nas lavouras, o valor da produção de banana no Acre foi de R\$ 7.802.000,00 (IBGE, 2002), o que representou uma diminuição no valor da produção no ano de 2001 de aproximadamente 47\% em relação ao ano anterior (Figura 2). Enquanto a diminuição da área colhida no ano de 2001 foi apenas 22,7\%, representando uma área de 1.516 ha. Nesse aspecto, houve uma redução de 50\% da área cultivada com bananeira nos municípios de Acrelândia e Plácido de Castro, os maiores produtores de banana do Estado do Acre (Sá et al., 2002).

Contudo, a bananicultura no Acre continua a ocupar a maior área plantada, com mais de 50\% da área ocupada, entre as espécies perenes apresentando destacada importância como alimento, geração de empregos e renda para a população rural. O valor da produção representou aproximadamente, 60\% e 40\% 


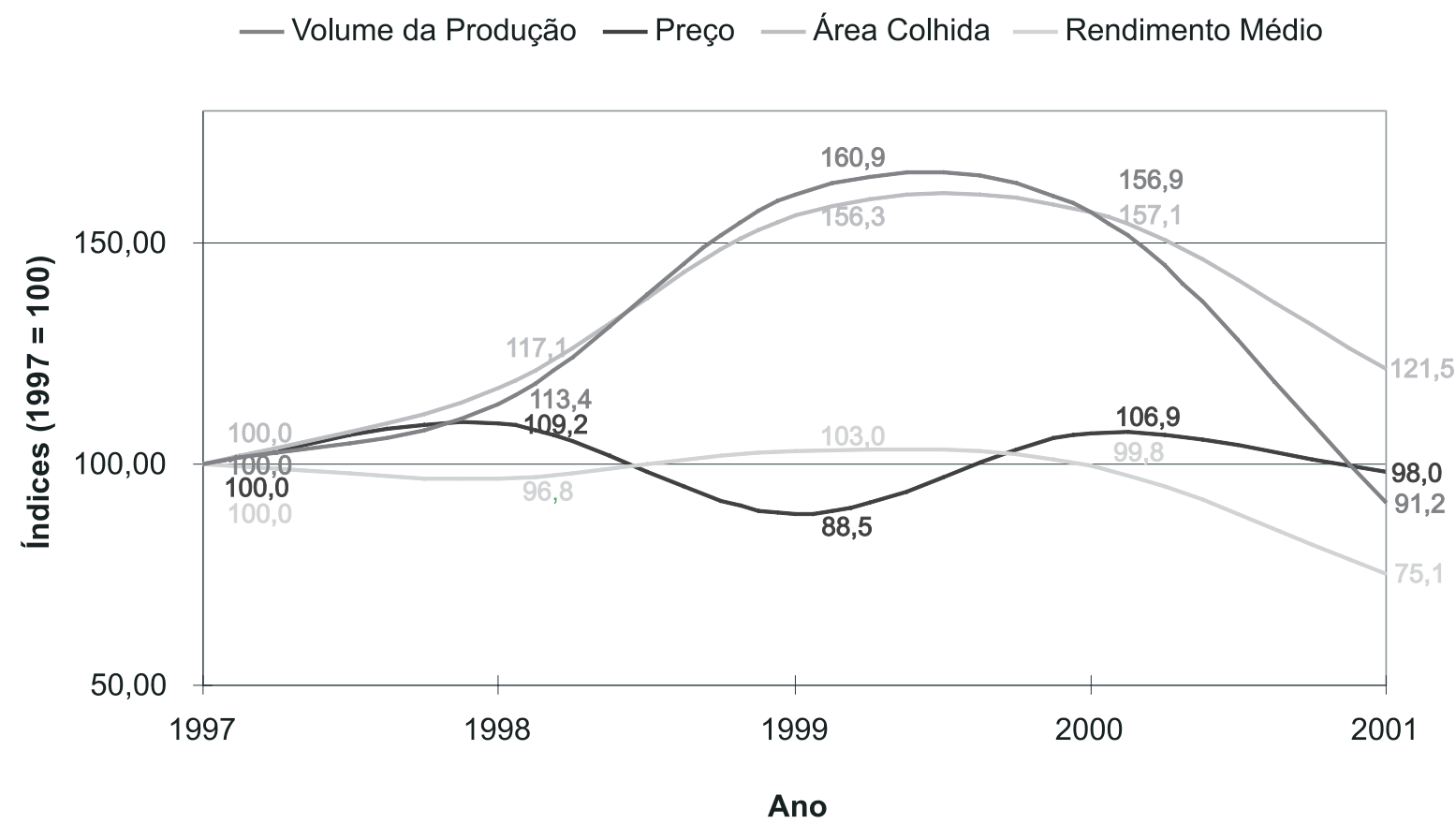

FIG. 1 - Índice relativo da variação estacional do volume da produção, área plantada e colhida, preço por cacho e rendimento médio para a cultura da banana (Musa spp.) no Estado do Acre, período 1997/2001, tendo por base o ano de 1997 (IBGE, 2002).

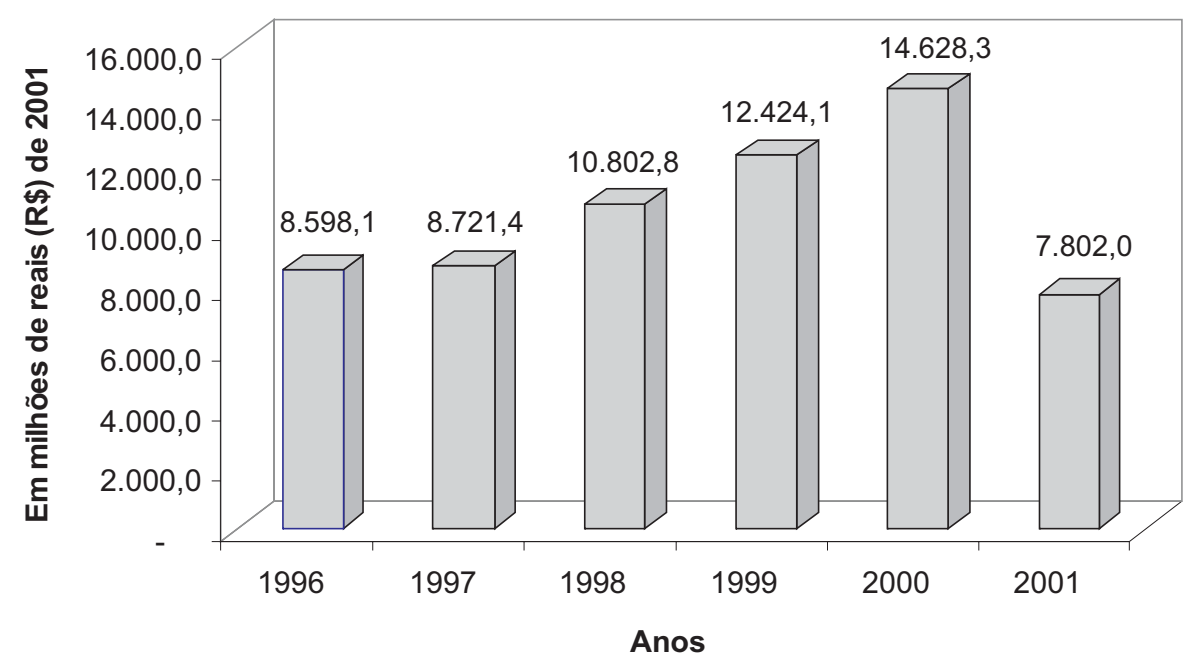

FIG. 2 - Valor da produção para a cultura da banana (Musa spp.) no Estado do Acre, corrigidos pelo IGP-DI para 2001, período 1996/2001 (IBGE, 2002).

do valor total da produção dos anos de 2000 e 2001, respectivamente. Sendo que no último ano gerou aproximadamente 186.912 dias de serviço, conforme estimativa dos coeficientes técnicos de produção da cultura (Sá et al., 2002).

A presença da sigatoka-negra no Acre reduziu a eficácia da cadeia produtiva da banana e poderá contribuir para o aumento do êxodo rural no estado, devido ser seu cultivo a principal fonte de renda de grande número de pequenos produtores.

Os impactos negativos do avanço da sigatoka-negra no Acre podem ser evidenciados no segmento "sistema de produção” nos anos de 2000/2001, com a diminuição da oportunidade da geração de emprego (aproximadamente 300 postos de serviços) e do valor da produção ( $\mathrm{R} \$ 6.826 .300,00)$, com repercussão nos demais segmentos da cadeia produtiva (Figura 2). Ressalta-se ainda, que os impactos negativos são atribuídos à doença, uma vez que no sistema tradicional de cultivo normalmente não são realizadas práticas culturais ou manejo adequado da cultura que previnam o ataque de pragas e doenças, como também não houve a influência de fatores exógenos, entre os quais se pode destacar o crédito bancário (Sá et al., 2002). 
Distribuição e impacto da sigatoka-negra na bananicultura...

\section{REFERÊNCIAS BIBLIOGRÁFICAS}

ACRE. Secrertaria de Estado de Ciência, Tecnologia e Meio Ambiente. Programa Estadual de Zoneamento Ecológico-Econômico do Estado do Acre. Zoneamento ecológico-econômico do Estado do Acre: recursos naturais e meio ambiente, documento final, $1^{\mathrm{a}}$ fase. Rio Branco: SECTMA, 2000. v. 1.

CAVALCANTE, M.J.B., GONDIM, T.M.S., CORDEIRO, Z.J.M., MATOS, A.P., HESSEL, J.L. \& SAMPAIO, F.R.V. Ocorrência da Sigatoka-negra em dez municípios do Estado do Acre. Rio Branco, AC: EMBRAPA-CPAF/AC, Comunicado Técnico, 107. 1999a. .

CAVALCANTE, M.J.B. \& GONDIM, T.M.S. A Sigatoka negra no Estado do Acre. EMBRAPA-CPAF/AC, Instrução Técnica, 22. 1999b.

CAVALCANTE, M.J.B., GONDIM, T.M.S., CORDEIRO, Z.J.M \& MATOS, A.P. Avaliação do comportamento de genótipos de bananeira à Sigatoka negra no Estado do Acre. Fitopatologia Brasileira 24:175. 1999c (Resumo).

CORDEIRO, Z.J.M. \& MATOS, A.P. Doenças fúngicas e bacterianas em plátanos. In: Alves, E.J. (Ed.) Cultivo de bananeira tipo terra. Cruz das Almas, BA: Embrapa Mandioca e Fruticultura, 2001. pp.79-97.

FERNANDEZ, M.R. Manual para laboratório de Fitopatologia. Passo Fundo, RS: EMBRAPA-CNPT, Documentos, 6, 1993.

GASPAROTTO, L., PEREIRA, J.C.R. \& TRINDADE, D.R. Situação atual da Sigatoka negra da bananeira. Fitopatologia brasileira 26:449. 2001. (Resumo)

GONDIM, T.M.S., AMARAL, E.F., ARAÚJO, E.A. \& SILVEIRA, M.M. Aptidão natural para o cultivo da bananeira no Estado do Acre. Rio Branco, AC: Embrapa Acre, Instrução Técnica, 34. 2001.
HAWKSWORTH, D.L., KIRK, P.M., SUTTON, B.C. \& PEGLER, D.N. Ainsworth \& Bisby's Dictionary of fungi. Eighth Edition. International Mycological Institute. CAB International. 1995.

INSTITUTO BRASILEIRO DE GEOGRAFIA E ESTATÍSTICA Sistema IBGE de Recuperação Automática - SIDRA. Banco de Dados Agregados. Produção agrícola municipal. Tabela 1612 Área plantada (hectare) e Tabela 1613 Lavoura permanente Disponível em: http:// www.sidra.ibge.gov/bda/tabela/protabl.asp Acesso em: 26 de março de 2002.

PEREIRA, J. C. R., GASPAROTTO, L., COELHO, A.F.S. \& URBEN, A. Ocorrência da sigatoka-negra no Brasil. Fitopatologia Brasileira 23:295. 1998.(Resumo)

MARIN, D. H., ROMERO, R. A., GUZMAN, M. \& SUTTON, T. B. Black sigatoka: An increasing threat to banana cultivation. Plant Disease 87:208-222. 2003.

RITZINGER, C.H.S.P., RITZINGER, R, CORDEIRO, Z.J.M \& CAVALCANTE, M.J.B. Ocorrência de Sigatoka negra da Bananeira em Rio Branco, Ac, Brasil. Fitopatologia Brasileira 24:450. 1999. (Resumo).

STOVER, R.H. Banana, plantain and abaca diseases. CMI, Kew, Surrey, England, 1972.

STOVER, R.H. \& SIMMONDS, N.W. Bananas. 3ed. Longman Scientific \& Technical, Essex, England. 1987.

TUITE, J. Plant pathological methods - Fungi and Bactéria. Minneapolis: Burgess. 1969.

SÁ, C.P., CAVALCANTE, M.J.B., SANTOS, J.C., NASCIMENTO, G.C. \& GOMES, F.C. Coeficientes técnicos e avaliação econômica para o sistema de produção tecnificado da banana no Acre. Rio Branco, AC: Embrapa Acre, Comunicado técnico. 151. 2002. 